\title{
The dust storm events recorded in DaQaidam region of Qaidam Basin since Late Glacial period: evidence from the grain size of lake sediment
}

\author{
Chunliang $\mathrm{Gao}^{1,2^{*}}$, Junqing $\mathrm{Yu}^{1,2}$, Xiuyun Min ${ }^{1}$, Aiying Cheng ${ }^{1,2}$ \\ ${ }^{1}$ Key Laboratory of Comprehensive and Highly Efficient Utilization of Salt Lake Resources, Qinghai Institute of Salt Lakes, Chinese \\ Academy of Sciences, Xining, Qinghai, 810008, China \\ ${ }^{2}$ Qinghai Provincial Key Laboratory of Geology and Environment of Salt Lakes, Qinghai Institute of Salt Lakes, Chinese Academy of \\ Sciences, Xining, Qinghai, 810008, China
}

\begin{abstract}
The paper focused on the study of detrital yellow layer from sediment profile D3 of DaQaidam Salt Lake, based on AMS ${ }^{14} \mathrm{C}$ chronologic and mineralogical methods, aimed to discuss the dust storm events recorded by detrital yellow layer of DaQaidam region since Late Glacial period. The results showed that the grain-size distribution curve displayed double kurtosis, the main peak (10 $\mu \mathrm{m}$ in average) reflected the fine-grained fractions into lake by fluviation, and the secondary peak $(>32 \mu \mathrm{m})$ reflected the coarse silt fractions into lake by wind effect and fluviation. Finally, the coarse-grained fractions $(>64 \mu \mathrm{m})$ from sediment profile D3 probably recorded the dust storm events since Late Glacial period.
\end{abstract}

\section{Introduction}

DaQaidam Salt Lake, a perennial water-body and salt playa, is located in a sub-basin of northern Qaidam Basin. The closed lake sediment, especially in arid and semiarid regions, which provided a proxy to reconstruct the regional dust storm events or sandstorms that occurred in historical periods [1-4]. In addition, the grain-size compositions of lake sediment were considered as good indicators for drought events and wind field conditions in geological history [5-7]. Here we report the results of sediment profile D3 from the centeral of DaQaidam Salt Lake in Qaidam Basin, using the mineralogical records, as well as AMS ${ }^{14} \mathrm{C}$ chronologic method, which aims to discuss the dust storm events in DaQaidam region recorded by detrital yellow layer from sediment profile D3 since Late Glacial period.

\section{Materials and methods}

\subsection{Sample descriptions}

This work focused on the bottom section from 453 to 655 $\mathrm{cm}$ of sediment profile D3 in the central of DaQaidam Salt Lake (figure 1). The sampling resolution varied from 1 to $5 \mathrm{~cm}$ according to the sediment characteristics. Three black muddy samples and all the detrital sediment samples were selected from detrital yellow layer of D3 prepared for $\mathrm{AMS}{ }^{14} \mathrm{C}$ dating and grain-size analysis, respectively. Finally, all the sediment samples were stored in cool rooms at $4{ }^{\circ} \mathrm{C}$.

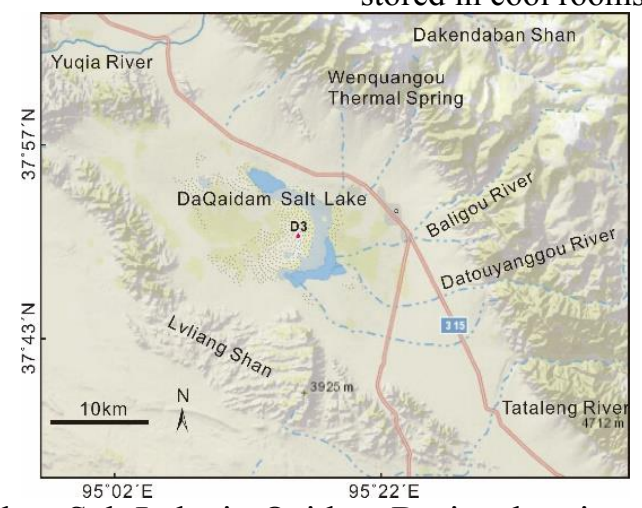

Figure 1. The map of DaQaidam Salt Lake in Qaidam Basin, showing the important geomorphologic features and the location of sediment profile D3. 


\subsection{Analytical methods}

Grain-size samples were measured by Malvern Mastersizer 2000 laser analyzer, with the measurement range of $0.01-1000 \mu \mathrm{m}$. The pretreatment followed the conventional chemical processes [8], i.e., samples $(0.2-$ $0.3 \mathrm{~g})$ were first treated with $30 \% \mathrm{H}_{2} \mathrm{O}_{2}$ to remove organic matter, and the carbonate was then removed using $10 \% \mathrm{HCl}$, finally ultrasonicated before the grainsize was measured. The Mastersizer 2000 automatically yields the median diameter and the percentages of related size fractions, with a relative error of less than $1 \%$. The experiment was conducted at Qinghai Institute of Salt Lakes, Chinese Academy of Sciences.

\subsection{The grain-size distribution}

The results showed that the grain-size distribution of lake sediment from profile D3 mainly ranged from 0 to $64 \mu \mathrm{m}$, and the average grain size is raletively smaller with a range of $7.2 \sim 35.3 \mu \mathrm{m}$. In addition, the sediment is mainly fine silt, from bottom to top, the grain-size of sediment profile D3 displayed a variation trend from fine to coarse (figure 2). Generally, the clay fraction $(<4 \mu \mathrm{m})$ in the sediment ranged from $6.3 \%$ to $29.0 \%$, the silt fraction $(4 \sim 32 \mu \mathrm{m})$ in the sediment ranged from $44.1 \%$ to $65.3 \%$, but the coarse silt $(32 \sim 64 \mu \mathrm{m})$ and sand fractions $(>64$ $\mu \mathrm{m})$ in the sediment only ranged from $15 \%$ to $55.5 \%$. Thus it can be seen that, the massive detrital yellow sediment from profile D3 of DaQaidam Salt Lake are clayey silt and fine silt on the whole, with the characteristics of fine-grained fraction.

\section{Results and discussion}

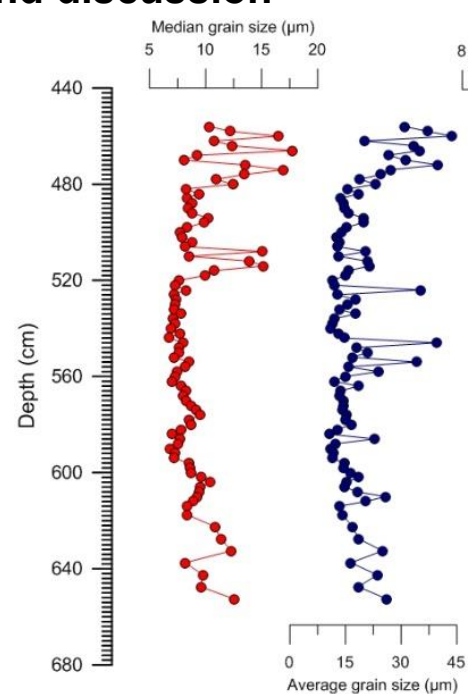

Figure 2. The vertical grain-size distribution of detrital yellow layer from sediment profile D3 in DaQaidam Salt Lake.

sediment ranged from 373 to $453 \mathrm{~cm}$ displayed the negative bimodal curves, indicating that the paleolake was in a relatively shallower water environment with strong hydrodynamic conditions, where the coarse grain arrived at the deposition point along with lake runoff, and the grain size of lake sediments was dominated by coarse-grained fractions.

In the western Qaidam Basin and DaQaidan region, a large area of paleolacustrine silt and clay strata were exposed to the surface. Due to the wind action, the winderoded Yardang landform has been formed (figure $4 \mathrm{a}$, $4 b)$. Especially, in winter and spring, due to the influence of cold air mass from Siberia, the ancient lacustrine strata in the western Qaidam Basin was severely eroded by the strong northwest wind and dust storm weather, with an annual erosion rate of $1.1 \mathrm{~mm}[4,11]$. As the fine sand (> $63 \mu \mathrm{m})$ transported by dust storm generally travels over a distance of 300 400 km [12], DaQaidam basin located in the northern depression of Qaidam Basin is an effective capture region for the above aeolian components consequently. In addition, the extensive pre-mountain alluvial fans around Qaidam Basin maybe other important source of lacustrine aeolian components [1315], while a large area of pre-mountain alluvial fans are 
developed around DaQaidam basin (figure 1). The study on Sugan Lake in Qaidam Basin showed that the coarsegrain fractions $(>63 \mu \mathrm{m})$ of lake sediment were used to indicate the evolution of regional dust storm events [2]. The coarse-grained fractions from lake sediment of Sugan Lake also recorded regional dust storm events, the fine-grained fractions mainly reflected the runoff, and the ultra fine-grained fractions represented atmospheric background dust and aerosol in the arid regions [3]. The grain-size fractions of dust storm in Lenghu region of Qaidam Basin indicated that the grain-size distribution curve displayed a multi-peak, and the coarse-grained fractions $(>63 \mu \mathrm{m})$ recorded regional dust storm events
[4]. In addition, the study on surface sediments from Daihai Lake of Inner Mongolia showed that the bimodal curve of grain size was formed under the joint influence of wind action and fluviation, and the small peaks of coarse-grained fractions $(>100 \mu \mathrm{m})$ reflected the input of exogenous wind-dust [1,7]. Qaidam Basin is a highincidence area of modern sandstorm, and Golmud city in the central Qaidam Basin underwent a dust storm in 2010 (figure 4c, 4d) [16]. The distance between Golmud and DaQaidam is only $165 \mathrm{~km}$, which evidenced that the coarse-grained fractions from lake sediments of DaQaidam Salt Lake maybe record regional dust storm events in historical periods.

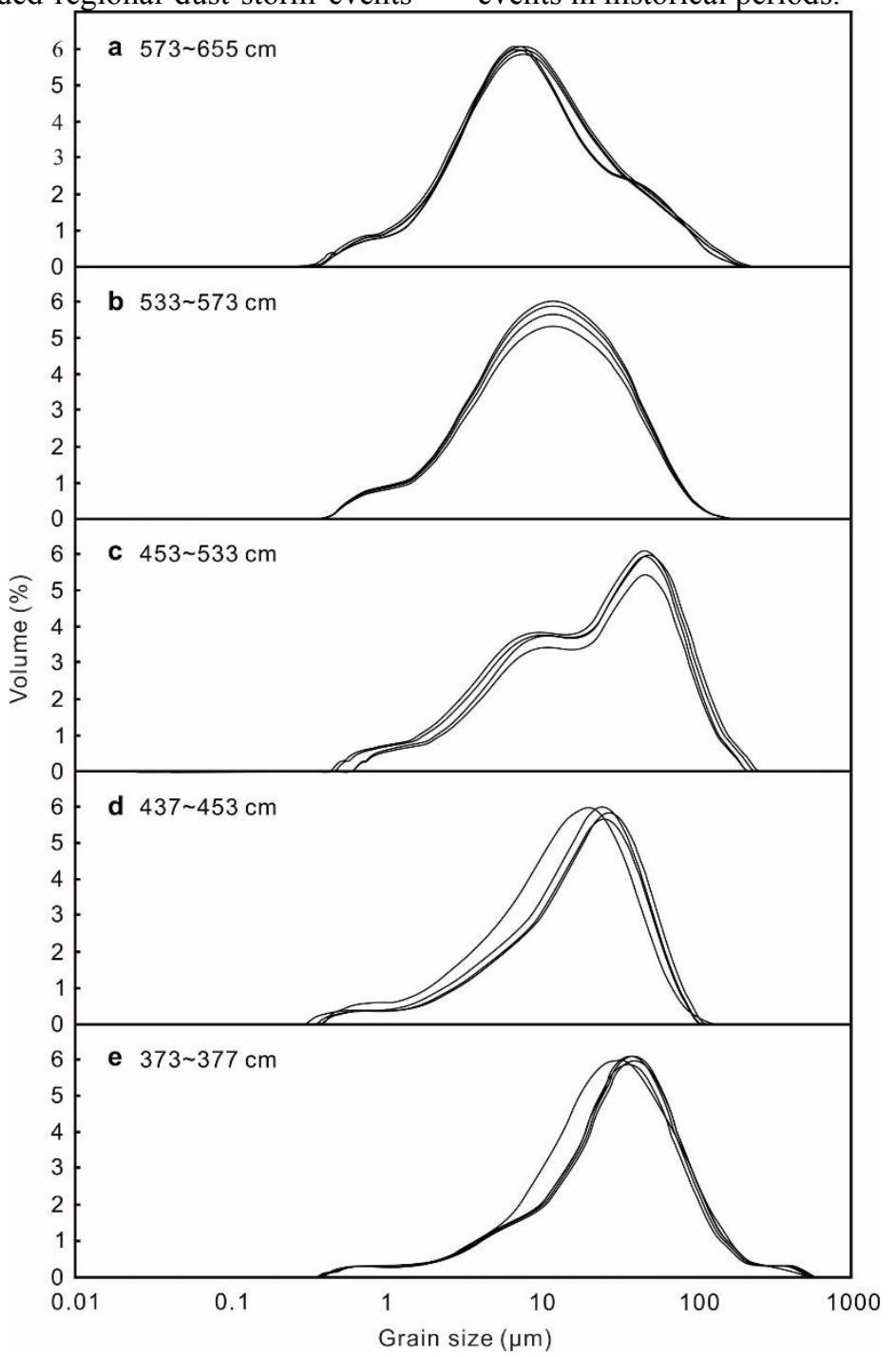

Figure 3. The grain-size distribution curves of detrital yellow layer from sediment profile D3 in DaQaidam Salt Lake.

Compared with the typical grain-size distribution curves in different sediments [4, 7, 17-18], and based on the grain-size parameters and mineral assemblages of detrital yellow layer from sediment profile D3 in DaQaidam Salt Lake, we considered that the main peak (10 $\mu \mathrm{m}$ in average) reflected the fine-grained fractions into lake by fluviation, but the secondary peak $(>32 \mu \mathrm{m})$ reflected the coarse silt fractions into lake by wind effect and fluviation. Based on the AMS ${ }^{14} \mathrm{C}$ chronology [19], we consequently concluded that the coarse-grained fractions $(>64 \mu \mathrm{m})$ from sediment profile D3 indicated an input of exogenous aeolian materials into the lake by dust storm weather, i.e., a dust storm event was recorded in the DaQaidam region since Late Glacial period. 


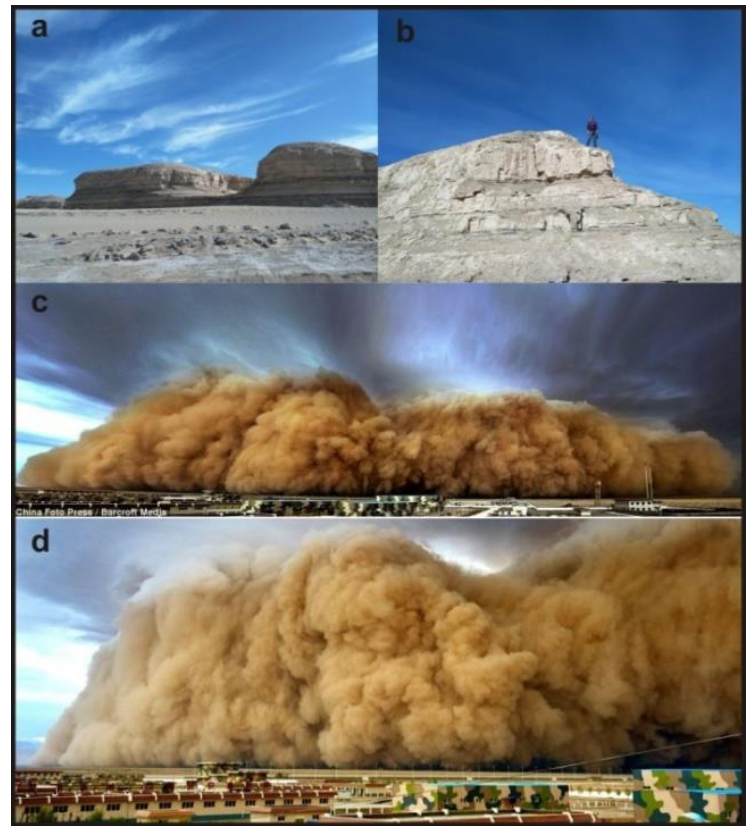

Figure 4. Geomorphologic feature of Yardangs $(a, b)$ and a dust storm occurred in Golmud city, the central of Qaidam Basin (c, d).

2. Qiang, M.R., Chen, F.H., Zhou, A.F., Xiao, S., Zhang, J.W., Jin, M. (2006) Preliminary study on dust storm events documented by grain size component of Sugan Lake sediments, north Qaidam Basin. Quatern. Sci., 26: 915-922.

The grain-size distribution curve displayed double kurtosis, the main peak $(10 \mu \mathrm{m}$ in average) reflected the fine-grained fractions into lake by fluviation, the secondary peak $(>32 \mu \mathrm{m})$ reflected the coarse silt fractions into lake by wind effect and fluviation, and the coarse-grained fractions $(>64 \mu \mathrm{m})$ probably recorded the dust storm events since Late Glacial period. In addition, Qaidam Basin as a high-incidence area of modern sandstorm is probably related to human activities such as vegetation atrophy and soil erosion [20]. The large amounts of desertification land caused the dust storm are widespread under weak wind conditions. Therefore, the hazards of human-caused dust storm and impacts on sustainable development should be emphasized.

\section{Acknowledgments}

We thank Liming $\mathrm{Xu}$ for laboratory assistance, Xianhu He for assistance with fieldwork. This work was supported by the National Natural Science Foundation of China (41501052, U1407206, 41471013), Qinghai Natural Science Foundation of China (2017-ZJ-928Q), the Second Tibetan Plateau Scientific Expedition and Research Program (2019QZKK0805) and Thousand Talents Plan of Qinghai Province (Grant to XY Min).

\section{References}

1. Jin, Z.D., Wang, S.M., Shen, J., Zhang, E.L., Wang, J., Chen, Y., Chen, S.T. (2000) Duststorm events in Daihai Lake area, Inner Mongolia during the past 400 years: evidence from grainsize analysis of lake sediments. J. Lake Sci., 12: 193-198.

3. Xiao, S., Chen, F.H., Qiang, M.R., Zhang, J.W., Zhou, A.F., Sun, D.H. (2007) Distribution pattern of grain size in surface sediments from Sugan Lake and its potential in recording aeolian dust in arid China. Acta Geogra. Sin., 62: 1153-1164.

4. Qiang, M.R., Lang, L.L., Wang, Z.T. (2010) Do fine-grained components of loess indicate westerlies: insights from observations of dust storm deposits at Lenghu (Qaidam Basin, China). J. Arid Environ., 2010, 74: 1232-1239.

5. De Deckker, P., Corrège, T., Head, J. (1991) Late Pleistocene record of cyclic eolian activity from tropical Australia suggesting the Younger Dryas is not an unusual climatic event. Geology, 19: 602-605.

6. Xiao, J.L., Inouchi, Y., Kumai, H., Yoshikawa, S. Kondo, Y., Liu, T.S., An, Z.S. (1997) Eolian quartz flux to Lake Biwa, central Japan, over the past 145,000 years. Quaternary Res., 48: 48-57.

7. Sun, Q.L., Zhou, J., Xiao, J.L. ( 2001) Grain-size characteristics of Lake Daihai sediments and its paleoenvironment significance. Mar. Geol. Quatern. Geol., 21: 93-95.

8. Lu, H.Y., An, Z.S. (1998) Pretreated methods on loess-palaeosol samples granulometry. Chinese Sci. Bull., 43: 237-240.

9. Sun, D.H., Bloemendal, J., Rea, D.K., Vandenberghe, J., Jiang, F.C., An, Z.S., Su, R.X. (2002) Grain-size distribution function of polymodal sediments in hydraulic and aeolian environments, and numerical partitioning of the sedimentary components. Sediment. Geol., 152: 263-277. 
10. Liu, X.Q., Dong, H.L., Yang, X.D., Herzschuh, U., Zhang, E.L., Stuut, J.W., Wang, Y.B. (2009) Late Holocene forcing of the Asian winter and summer monsoon as evidenced by proxy records from the northern Qinghai-Tibetan Plateau. Earth Planet. Sc. Lett., 280: 276-284.

11. Kapp, P., Pelletier, J.D., Rohrmann, A., Heermance, R., Russell, J., Ding, L. (2011) Wind erosion in the Qaidam basin, central Asia: implications for tectonics, paleoclimate, and the source of the Loess Plateau. GSA Today, 21:410.

12. Yang, S.L., Ding, Z.L. (2004) Comparison of particle size characteristics of the Tertiary 'red clay' and Pleistocene loess in the Chinese Loess Plateau: implications for origin and sources of 'red clay'. Sedimentology, 51: 77-93.

13. Sun, J.M., Li, S.H., Muhs, D.R., Li, B. (2007) Loess sedimentation in Tibet: provenance, processes, and link with Quaternary glaciations. Quaternary Sci. Rev., 26: 2265-2280.

14. Guan, Q.Y., Pan, B.T., Gao, H.S., Li, N. Zhang, H., Wang, J.P. (2008) Geochemical evidence of the Chinese loess provenance during the Late Pleistocene. Palaeogeogr. Palaeoclimatol. Palaeoecol., 270: 53-58.

15. Kaiser, K., Lai, Z.P., Schneider, B., Reudenbach, C., Miehe, G., Brückner, H. (2009) Stratigraphy and palaeoenvironmental implications of Pleistocene and Holocene aeolian sediments in the Lhasa area, southern Tibet (China). Palaeogeogr. Palaeoclimatol. Palaeoecol., 271: 329-342.

16. Bates, C. (2010) Desert storm: huge cloud of sand descends on Chinese village. Daily Mail.

17. Jiang, H.C., Ding, Z.L. (2010) Eolian grain-size signature of the SiKouzi lacustrine sediments (Chinese Loess Plateau): implications for Neogene evolution of the East Asian winter monsoon. Geol. Soc. Am. Bull., 122: 843-854.

18. Sun, D.H., Bloemendal, J., Rea, D.K., An, Z.S., Vandenberghe, J., Lu, H.Y., Su, R.X., Liu, T.S. (2004) Bimodal grain-size distribution of Chinese loess, and its palaeoclimatic implications. Catena, 55: 325-340.

19. Gao, C.L., Yu, J.Q., Min, X.Y., Cheng, A.Y., Hong, R.C., Zhang, L.S., Li, T.W. (2019) The sedimentary evolution of Da Qaidam Salt Lake in Qaidam Basin, northern Tibetan Plateau: implications for hydro-climate change and the formation of pinnoite deposit. Environ. Earth Sci., 78: 463.

20. Andreae, M.O. (1996) Raising dust in the greenhouse. Nature, 380: 389-391. 